The University of Southern Mississippi

The Aquila Digital Community

Faculty Publications

$5-10-2018$

\title{
PETA, Rhetorical Fracture, and the Power of Digital Activism
}

Ashli Q. Stokes

University of North Carolina at Charlotte, aqstokes@uncc.edu

Wendy Atkins-Sayre

University of Southern Mississippi, wendy.atkinssayre@usm.edu

Follow this and additional works at: https://aquila.usm.edu/fac_pubs

Part of the Communication Commons

\section{Recommended Citation}

Stokes, A. Q., Atkins-Sayre, W. (2018). PETA, Rhetorical Fracture, and the Power of Digital Activism. Public Relations Inquiry, 7(2), 149-170.

Available at: https://aquila.usm.edu/fac_pubs/15141

This Article is brought to you for free and open access by The Aquila Digital Community. It has been accepted for inclusion in Faculty Publications by an authorized administrator of The Aquila Digital Community. For more information, please contact Joshua.Cromwell@usm.edu. 


\section{PETA, rhetorical fracture, and the power of digital activism}

The rise of digital social advocacy ${ }^{1}$ offers activists additional opportunities to shift public opinion and challenge organizational behavior, providing more opportunities to theorize activism within public relations scholarship. Digital technologies accelerate some traditional activist practices, such as establishing legitimacy for causes and issues, attracting supporters and building collective identity, overcoming power and resource imbalances to mobilize like-minded publics, and achieving significant outcomes (Hon, 2015; Sommerfeldt, 2011; Uysal and Yang, 2013; Yang and Taylor, 2010). Activists use social media to promote their causes at local, state, and national levels (Mundy, 2013), and to agitate, counter, and shift the status quo (Coombs and Holladay, 2012; Jackson and Welles, 2015; Mundy, 2013). Digital technologies fundamentally change activism in certain ways, removing traditional media gatekeepers and forcing corporations to respond faster to concerns to encourage corporate change (Hon, 2015; Veil et al., 2015). Digital advocacy also allows nonprofessionals to create successful campaigns, to eschew formal organization (Guo and Saxton, 2014), and to challenge what it means to have long-term allegiance around an issue (Hon, 2015). Digital technologies thus clearly enhance activism, but activists' ability to quickly produce digital messages that exploit a target’s weaknesses, deploying their own tools and content to disrupt their narratives, needs more exploration. 
One of the clearest examples of digital activists disrupting an opponent's narrative is shown in the protracted battle between People for the Ethical Treatment of Animals (PETA) and SeaWorld. SeaWorld's most famous orca, Tilikum, had the distinction of being the world's deadliest whale, the subject of a CNN Films documentary titled Blackfish, and the primary reason that SeaWorld has been on the losing end of an ongoing public relations controversy since 2013. Blackfish became one of PETA’s most powerful rhetorical tools in attacking SeaWorld, telling Tilikum’s story and highlighting former SeaWorld employees who provided damaging insider information. PETA's use of the documentary and resulting media attention triggered “a profound crisis for SeaWorld, which had built its brand on the back of killer whales” (Wallace, 2016: para. 4) and by 2015, a Consumerist poll ranked SeaWorld as the third most-hated business in America (Geiling, 2015).

The PETA/SeaWorld controversy does more than provide another example of poor corporate public relations decision-making made in light of an activist group’s savvy use of digital technology (e.g., Duhon et al., 2016). We argue that the case helps explain how digital technologies fundamentally change activism, whereby activists can use rhetorical fracturing, or quickly using digital media to puncture a target's narrative, to create messages that challenge an opponent's legitimacy to cultivate public opinion, thereby 
pressuring corporate policy change. Recent activism scholarship points out how digital media transform organizational-activist relationships in profound ways, but this essay contributes to a gap in public relations scholarship by showing how strategic, messagelevel digital activism helps contribute to broad societal change. Indeed, given that SeaWorld's stock was down nearly 40\% in 2015 and "is about 50\% below its all-time high” (La Monica, 2015), its profits were down 84\% in 2015 (Neate, 2015), and attendance has fallen more than 7\% at its parks (Bryan, 2016), the case illustrates how digital activist campaigns help reshape societal understanding of a controversial issue such as using animals for entertainment.

We first contextualize the PETA/Sea World controversy. We then interweave the changing media environment with literature describing how activists challenge an opponent's legitimacy surrounding an issue, arguing that activists upend the power balance by exploiting organizational weaknesses through the strategy of rhetorical fracture. After describing our rhetorical methodology, the analysis details how PETA deploys rhetorical fracture in order to challenge SeaWorld's narrative, helping shift consumer opinion, and moving it to radical action. PETA's attacks on SeaWorld act as an exemplar for digital activism campaigns that employ strategic de-legitimizing messages to remain oppositional and change relationships between corporations, activists, and stakeholders. 


\section{Case Background: PETA, SeaWorld and the Rhetorical Uses of Blackfish}

\section{PETA}

Established in 1980, PETA has quickly grown to be one of the most recognized international animal rights organizations. The organization became adept at crafting public controversy in order to draw attention to animal rights arguments and begin conversations about what it considers to be animal cruelty, including wearing fur, testing on animals for drug manufacture, and making animals perform for entertainment. Although PETA initially operated solely in the United States, the organization now has campaigns in the U.K., France, Germany, Netherlands, India, Australia, Asia and also has a “Latinx”focused page. Targeting companies and government industries in these various locations, PETA has influenced conversations surrounding animal rights on a grand scale (AtkinsSayre, 2010).

Although considered to be one of the more radical animal rights groups due to its calls for thorough change (Stewart, Smith, and Denton, 2007), what PETA's campaigns primarily do is gradually shift animal welfare practices through its "full court press" on target organizations. The group uses rhetorical and economic pressure to bring about change, pushing SeaWorld in ways that may not fully satisfy PETA activists (many want the parks shut down) but result in increased awareness, concern, and action among the general public about animal rights issues. Its attacks on SeaWorld and other target 
organizations, along with other activist groups, also help change gradually what "animal welfare/rights” means outside the entertainment industry, including animal testing for cosmetics, reform in horse-racing, and treatment of lab animals, to name a few examples. The group’s work has resulted in a number of significant breakthroughs for the animal rights movement, including a positive ruling by the U.S. Supreme Court for lab animal treatment standards (Atkins-Sayre, 2010). Most recently, the group celebrated the shuttering of the 146-year-old Ringling Bros. Circus after targeting that organization for more than 30 years. In a news release immediately following that company's announcement, PETA (“It’s Over,” 2017) warned others: “All other animal circuses, roadside zoos, and wild animal exhibitors, including marine amusement parks like SeaWorld and the Miami Seaquarium, must take note: society has changed, eyes have been opened ... and we know it is wrong to capture and exploit them” (para. 2). The group is committed to long-term social change regarding animal treatment, devoting significant attention to changing the practices of a company like SeaWorld. Since 1998, the organization has targeted the company, relentlessly attacking it through protests, boycotts, and viral campaigns.

SeaWorld 
PETA's attack on SeaWorld challenges the park’s business model. When SeaWorld opened in 1964 in San Diego, California, the creators of the park were "[d]etermined to create planet Earth’s most ambitious marine park” (Friedersdorf, 2014: para. 9). The park was certainly successful, becoming one of the most recognized animal entertainment venues. Established by Milton Shedd and colleagues, the park has since expanded to two other locations, with additional offshoots across the United States and around the world (Friedersdorf, 2014). Shedd, an ocean conservationist, claimed that business success depended on the ability to "exploit and stoke humans’ natural interest in the ocean” (Friedersdorf, 2014: para. 28). SeaWorld reiterates that message even today, arguing that its parks “inspire millions to celebrate, connect with and care for the natural world we share through the power of entertainment” (SeaWorld, "What we do”: para. 1).

This corporate message helped craft SeaWorld’s overriding narrative over the years, perhaps attracting more visitors, but its story would become a rhetorical liability once PETA seized upon the opportunity the release of the Blackfish documentary provided. As Bowen and Heath (2007) remind us, corporate narratives “relay belief systems and values, express expectations, and normatively guide individual and collective choices” (p. 75). In its initial story, SeaWorld viewed animals as entertainers and humans as consumers of that entertainment. Beyond “mere” entertainment, though, SeaWorld used 
this interaction between human and animal to position itself as a conservationist; the corporation was composed of people who understood animals (scientists and animal behaviorists) and who cared for the animals and looked out for their best interests (trainers, veterinarians, and animal lovers more broadly). Once PETA capitalized upon the release of Blackfish, SeaWorld's conservation/entertainer positioning was challenged.

The release of the Blackfish documentary made SeaWorld an even more highpriority target of animal rights rhetoric. SeaWorld initially attempted repeatedly to respond to the controversy with an initial "sputtering and ineffective” reaction (Wallace, 2016: para. 15). The organization countered with newspaper and television public relations image advertisements, a devoted web site section, and a YouTube channel with videos that claimed that "the truth is in” its “parks and people.” Nevertheless, Blackfish allowed PETA to double down on SeaWorld through its typical rhetorical shock tactics, including its “SeaWorld of Hurt” website, news releases, and ongoing social media ridicule, deepening the organization's woes. By 2016, the company had a new CEO, announced that it would stop breeding orcas, and faced a dubious future, as ongoing cultural "soulsearching” forced questions about the use of animals for entertainment (Wallace, 2016: para. 15). Blackfish 
The documentary itself was powerful, but it was the use of the film as a rhetorical tool that significantly shifted the narrative surrounding the use of animals as entertainment. PETA had long organized against SeaWorld, but PETA’s Senior Vice President Lisa Lange “acknowledges the campaign really took off after Blackfish” (in Allen, 2015: para.11). Consequently, PETA not only helped spread the news about the documentary (thereby increasing the number of viewers), but also used the documentary as fodder for its own campaigns. As Caty Chattoo (2017) argues, “The major contribution of grassroots infrastructure to the Blackfish movement came from PETA... and in fact, the intersection between the film and the organization's activism may have amplified the ongoing impact dramatically” (para. 5). Because of this interdependence, PETA and the Blackfish message became almost synonymous. By deploying Blackfish as its own weapon in the digital realm, PETA highlighted its attack on SeaWorld's corporate narrative, emphasized the animal rights issue in the discussion, and challenged SeaWorld’s legitimacy.

\section{Literature Review: Digital Media and Rhetorically Fracturing Legitimacy}

\section{Digital Media and Activism}

Public relations practitioners and scholars agree that PETA’s type of digital activism campaigns need more attention. Digital media create new contexts that provide different ways to interact with stakeholders and influence public policy that PETA's 
campaigns embody (DeLuca et al., 2012; Gong, 2015; Guo and Saxton, 2014; Hon, 2015). A Senior Vice President for Ketchum Public Relations concisely observes what others in the disciplinary scholarship have confirmed: that four hallmarks of the media landscape are shifting to create openings for activists with an understanding of technology. First, a growing sense of public empowerment and mass amateurization (Earl and Kimport, 2011; Shirky, 2008) makes it easier for activists to communicate more directly and easily with a range of stakeholders to provoke established institutions (Henderson, 2005); indeed, as Hon (2015) puts it, “anyone can be a publisher, videographer, or photographer” (p. 300). Even less engaged publics are able to retweet a more committed activist's views, spreading rapid awareness of a cause and the ability to "pile on" accusations to "keep the conversation going” (Hon, 2015: p. 300; Madden, Janoske, and Briones, 2015; Shirky, 2008). Social media quickly spread information (sometimes misinformation), fueling anger and outrage (Cheng, 2016; Coombs and Holladay, 2007), making it difficult for organizations to have narrative control, and cultivating negative perceptions of an organization over time (Kent, 2010; Schwarz, 2012). This gradual “death by a thousand cuts” leads organizations to fall victim to spiraling individual indignation, constituting big headaches. 
The growing public empowerment through digital media creates three additional openings. The public's fleeting attention and desire for "snackable” soundbites and superficial visuals, for instance, leads to more intense but shorter crisis cycles. Food chain Chipotle, for example, faced huge initial dips in sales following its E. coli outbreak but then slowly recovered as consumers "moved on" to snippets from the next social media crisis (e.g., Veil et al., 2012). Next, traditional news has become less organizationally driven and more individually driven, creating crowdsourced elites that contribute to stakeholder outrage and heighten these intense cycles (Jackson and Wells, 2015; Papacharissi and Oliveria, 2012). Pseudo-experts, together with citizen journalists sharing stories with a single keystroke (Shirky, 2008), find platforms through social media and inclusion in traditional news broadcasts. Finally, digital empowerment means that stakeholder trust must be continually earned in more public ways. Companies are pressured to offer more transparency and battle Internet echo chambers with likeminded groups sharing similar content, making maintaining this trust difficult. Indeed, a single tweet can become a collection that works together to fuel corporate distrust (Jackson and Wells, 2015). Sometimes, these digital media characteristics may merely accelerate activism, but they may also fundamentally change it (Hon, 2015), reducing the need for 
central organization and leadership, the costs for activist participation, and the need for resources.

Message-Level Digital Activism and Legitimacy

Technologies themselves do not change activism; rather, it is what an activist does with them that needs attention. Activism scholarship examines the use of social media among advocacy organizations, but tends to focus on the type of platform used, rather than actual message content (Bortree and Seltzer, 2009; Edwards and Hoefer, 2010; Greenberg and MacAulay, 2009; Obar et al., 2012; Petray, 2011). Guo and Saxton (2014) focused on “message-level” digital advocacy because of the "striking” need to explore how these features are employed, but their quantitative approach located types of advocacy tactics (e.g., public education, coalition building) and was largely descriptive (p. 58). Hon (2015) provided a conceptual model of digital advocacy, but grouped message level "strategies and tactics” into one broad component and suggested a linear understanding of the public relations process. We argue instead that the back and forth between targets and activists must also be captured, with digital advocacy fundamentally changing what messages activists are able to create through rhetorical fracture. The Blackfish controversy provides an excellent opportunity to explain how activists deploy strategic messages in the digital realm. 
Indeed, although PETA first brought a lawsuit against SeaWorld in October 2011, until the launch of Blackfish in 2013, its "SeaWorld of Hurt" website did not receive much attention. The group's use of the movie to cultivate attention to the animal welfare issue in the digital realm highlights how activists capitalize on this environment, providing a clear example of how an unresolved issue (SeaWorld's treatment of its orcas) morphed into a crisis for the company. An issue, or a "contestable matter of fact, value, or policy” thus forms the heart of activism (Smith and Ferguson, 2010). ${ }^{2}$ Issues are considered to be a primary feature of an activist group’s environment and provide the “grounds for activist organizations’ goals;” issues management, then, the study of how activists identify, develop, and resolve these disputed societal questions, “dominates most scholarly work on activism” (Heath and Waymer, 2009: p. 233; Smith and Ferguson, 2010: pp. 400-401). Organizations on either side of a debate use issues management to identify issues and develop responses, rhetorically attempting to influence public debate about solutions advantageous to the organization (Brooks and Waymer, 2009; Heath, 2006). Scholars point out that certain rhetorical strategies nurture an organization's position or stance through what has been called the issue-management lifecycle, whereby organizations adopt different argumentative strategies to advocate for their position depending on whether they are trying to establish a topic as one in need of address, garner additional supporters, gain 
media coverage, or push for a particular resolution (e.g., Crable and Vibbert, 1985; Heath, 1997; Smith and Ferguson, 2001). Though PETA had been nurturing its issue against SeaWorld for years, it digitally capitalized on Blackfish to help garner media attention, moving the issue to the critical phase in the lifecycle to create a crisis, or "a violation of societal norms/expectations” for SeaWorld, successfully challenging the legitimacy of its practices and culminating in policy change (Coombs, 2006: p. 249).

Indeed, scholars have explored how activists must establish an issue’s legitimacy, or acceptance/congruence with society, in the early phases of the issues management lifecycle, marshalling support from more and more segments of the public (Crable and Vibbert, 1985; Smith and Ferguson, 2010). Activists use a variety of strategies to challenge their target’s legitimacy, engaging with organizations in a "legitimacy dance" with opponents "questioning the other's issues, motives, and right to exist” (Smith and Ferguson, 2010: p. 401). These strategies that create a tension between what is and what ought to be, ${ }^{4}$ have been explored in a variety of contexts, with Condit and Condit (1992), for example, exploring how activists chip away at a target's legitimacy, Bostdorff (1992) examining how activists attempt to take the "moral high road” to question an opponent's legitimacy, Henderson (2005) exploring how activist groups attempt to question the legitimacy of genetic engineering in New Zealand, and Heath and Waymer (2009) looking 
at how activists correct overly positive interpretations of conditions. Importantly, in a more recent study, Smith and Ferguson, raised “de-legitimacy” from one of Coombs’ (1992) original "bases" of legitimacy to a strategy in its own right, with opposing groups relying on de-legitimation strategies to argue about the most appropriate locus for making public policy decisions over the issue of fracking in Pennsylvania.

Rhetorical fracture, or quickly using digital media to puncture a target’s narrative, is a particularly digital de-legitimacy strategy, where activists rely on the digital environment to de-legitimize a target more easily. Fracture thus embodies some of the legitimacy strategies identified in the literature but capitalizes on institutional weaknesses (like corporate size, legal requirements, and the like) to deploy them in the digital media environment, presenting serious challenges. The digital landscape provides more openings that allow activists to fracture through verbal "atom cracking," juxtaposing incongruous words, ideographs, and arguments to shatter “pieties,” or commonly held beliefs (Burke 1959; Campbell, 1998). This activist subversion, or "using the master's tools to undermine, even sabotage, the master’s house” (Campbell, 1998: p. 112) denaturalizes accepted societal definitions. Rhetorical fracture, however, further capitalizes on a narrative’s digital presence; here, activist organizations digitally fracture common frames/definitions used by their targets in order to erode dominant interpretations and encourage changes to corporate 
practices (turning SeaWorld’s use of the word “tank” into “animal prison,” for example). The altered media landscape allows groups like PETA to be more nimble, incorporating creativity, humor, and embarrassment to fuel individual indignation and challenge SeaWorld’s narratives. As we show, activists may use a variety of techniques to “atom crack," co-opting institutional advantages and challenging their adversaries' version of reality (Olson et al., 2008: p. 245). Activists have been challenging targets for years by using their messages against them to erode organizational narratives (Alinksy, 1971; Burke 1959; Campbell, 1998); the digital environment, however, accelerates and simplifies this process. With a keystroke, editing software, and social media at their disposal, activists use rhetorical fracture to puncture holes in corporate narratives in significant ways, including claims to legitimacy, justification for actions, and replacing one narrative with another. In the Blackfish controversy, PETA fractures SeaWorld's narrative through remediation and hypermedia to forward its attack on SeaWorld’s legitimacy. Remediation is the process by which media is taken from one form and used in another, preventing the conventions of a forum from operating independently from other cultural discourses and disrupting the way it typically functions (Bolter and Grusin, 1999). The strategy uses an organization's media in a new way or place (here, by using Blackfish and SeaWorld's content on PETA's websites), preventing their ability to stand as “proof” or evidence of 
corporate behavior or commitments and calling into question its ethos. ${ }^{5}$ In light of the increased expectations to establish trust in a digital environment, PETA uses remediation to further disrupt positive views of SeaWorld. In its quest to fracture SeaWorld's legitimacy, PETA also deployed hypermediacy, or "a style of visual representation whose goal it is to remind the viewer of the medium” (Bolter and Grusin, 1999: p. 272). Here, opponents “add on” to a particular media portrayal or medium, using a target’s own communication tactics (website, news releases, and the like) to offer critique. Hypermediacy can play an important role in lessening public trust and fueling outrage, also meeting digital culture expectations. These two techniques helped bring a supercharged legitimacy challenge to SeaWorld, challenging its relationship with stakeholders.

\section{Methodology}

In order to better explain the ways that PETA was successful in encouraging SeaWorld to change its practices through fracturing public acceptance of its narrative, we rhetorically analyze the back and forth "sparring” between the two organizations. Rhetorical analysis examines how discourse is used to shape meaning and to influence beliefs and actions. Although theoretical approaches differ, rhetorical criticism is the study of what is persuasive (Campbell \& Burkholder, 1997), “designed for the systematic investigation and explanation of symbolic acts and artifacts for the purposes of 
understanding rhetorical processes” (Foss, 1996: p. 8). Criticism is also described as an "art," "realizing the sorts of strategic choices that can and must be made, and determining the strategic and ethical quality of the responses that are made in the face of those choices" (Heath, 2009: p. 43). Rhetorical criticism is used here to analyze a multi-year archive of SeaWorld and PETA public relations activity, clarifying how each party sought to convincingly shape knowledge and opinions and motivate action (Heath, 2009; Stokes, 2013). More specifically, to understand the rhetorical work at play in this controversy, we compared the communicative elements (press kits, including press releases, websites, television and newspaper advertisements) following the release of the Blackfish documentary in 2013 until SeaWorld announced its decision to stop breeding orcas in 2016. In particular, we focused on SeaWorld's material that addressed claims made in Blackfish: its corporate site, its YouTube channel (with documentaries and videos), and its national newspaper and television image advertisements. Similarly, we examined all PETA messages targeting SeaWorld following Blackfish's release, including its "SeaWorld of Hurt” website, its main activist site devoted to SeaWorld, its YouTube channel, and its national television image advertisements. In all, we analyzed approximately 200 rhetorical artifacts, analyzing PETA and SeaWorld's content devoted specifically to responding to the claims raised by Blackfish. 
Rhetorical criticism generally follows four steps. The first step is descriptive analysis, which closely examines texts looking for general themes and persuasive patterns; critics then account for how the texts address or respond to a particular history and context. Next, critics draw from different theoretical approaches to best illuminate a text in step three, and finally make an argument based on the previous steps (Campbell \& Burkholder, 1997). As PETA sought to disrupt SeaWorld's story about animal welfare through Blackfish, this analysis employs narrative criticism to better understand how rhetorical fracture challenged its corporate positioning. Scholars use this method to better understand how organizations attempt to exert control in the face of crises like SeaWorld's, examining how each crisis exhibits a "peculiar set of narrators, plot, moral (theme), characters, location (setting or scene), and relationships” (Heath, 1994, p. 75). Based on Fisher’s (1987) narrative paradigm that assumes human communication is a story, these analyses explore the "symbolic interpretations of aspects of the world occurring in time and shaped by history, culture, and character” that justify or legitimize organizational behavior (p. xi). Typically, critics using narrative criticism look for whether stories are believable, consistent and coherent (narrative probability), and resonate with an audience's beliefs/assumed facts (narrative fidelity) to persuade audiences to support a perspective. We were particularly interested in how the opponents tried to delegitimize the other's 
narrative and whether the accounts given were "plausible and justified under the circumstances” (Fisher, 1985, 1987; Heath \& Palenchar, 2009: p. 296).

As a result, we first looked for the identifying features of the collection of artifacts, focusing on the opponent’s narratives (Berkowitz, 2003; Condit, 1994; Foss, 1996). Upon noting that PETA continually attempted to disrupt SeaWorld's story through its use of its opponent's media, we sought to explain this process through remediation and hypermediation. Rhetorically analyzing the collection of texts through these principles, we map out how PETA delegitimized SeaWorld's corporate story and ultimately affected policy as well, demonstrating how rhetorical fracture must be considered in developing and responding to digital activism.

\section{Analysis: Digitally Fracturing SeaWorld's Story}

\section{Phase One: Remediating Blackfish}

The strategy of rhetorical fracture is central to many of PETA's campaigns since the group is concerned with shifting perceptions about animals and changing the conversation to support animal welfare. Animal rights issues already had a community of supporters, but "the opportunity was right for cultivating new activism” through Blackfish (Chattoo, 2017: para. 5). Thus, soon after the release of Blackfish in 2013, PETA's existing “Sea World of Hurt” website became more of a priority for the organization, providing a 
platform for its news releases and advertisements attacking the amusement parks, with PETA issuing more than 110 news releases attacking SeaWorld starting in 2013. Yet Blackfish quickly became PETA’s “primary source,” the tool it remediated to develop rhetorical fracture, which simultaneously added to the persuasive strength of the film itself and also bolstered its own claims against SeaWorld (Awesomeocean, n.d.: para.7). PETA used remediation in attempting to change the way the audience viewed SeaWorld upon release of the film, replaying the Blackfish trailer on its sites, providing a video review (using scenes from the documentary itself) and helping supporters organize viewing parties. Through each of these activities and more, PETA remediates Blackfish as evidence of its claims of animal cruelty. It is more than the group's ability to reuse and promote the footage that was persuasive however, with the narrative of Blackfish itself providing the group with the ability to, as one observer put it, "reach outside the animal-welfare community to new audiences” (Chattoo, 2017: para. 8).

Indeed, the reason Blackfish became such a powerful rhetorical tool for PETA was because it appeared to be a raw, true representation of the industry. Documentary-style films are persuasive because they ultimately appear to put forth a "window on the world" perspective. As Nichols (1991) writes, "Something of reality itself seems to pass through the lens and remain embedded in the photographic emulsion” (p. 5). Viewers are more 
likely to see the images as reflecting reality. This form in fact prepares viewers for an argument, framing the world in a particular way and presenting that image as reality. For that reason, the message that documentaries create can be very persuasive.

PETA's ability to remediate the documentary’s dramatic footage casts doubt on the narrative fidelity and probability of SeaWorld's story. It is important to appreciate the footage that PETA was able to select from in designing its own materials. Blackfish opens with an underwater shot. Against the backdrop of dramatic music, a 9-1-1 phone call is played which explains that there is an emergency at Sea World Orlando. "We need... uh... someone to respond for a dead person to SeaWorld. Uh... a whale has eaten one of the trainers" (as the voice begins to break). Instantly, the shot transitions to an energetic orca show, with the whale emerging from the water and the crowd cheering. For a brief moment, the viewer is allowed to remember the SeaWorld that the park wants you to experience-a stadium filled with happily performing orcas and elated crowds. As is typical in documentaries, however, the film then moves quickly through a number of different experts who testify about SeaWorld's practices. The names and titles splashed across the screen explain to viewers that this testimony comes from former Sea World trainers. The featured speakers mention their love for their former jobs, their joy at having worked with the animals, and their continued concern for the animals, establishing their 
credibility as experts on the topic. The film then runs through a long series of shots that show the former trainers working with the whales, including a senior trainer who was killed at Shamu stadium. With the ethos of the film established, the documentary begins to tell the story of the corporation versus those who have devoted their lives to their jobs and the animals, questioning SeaWorld's claims of being a champion for animals. The death of the trainer is explained, as are the dangerous situations involving other trainers at Sea World. Along with the testimony from the former trainers, the film pulls in audio from depositions, seeming to put the corporation on trial while on screen. The film then proceeds to develop a case against SeaWorld, focusing on the whale's inhumane treatment, explaining that all of the orcas are housed in extremely small tanks and forced to perform in order to receive food.

The testimonies and the visuals work together to cast doubt on SeaWorld's narrative, encouraging the audience to question SeaWorld's commitment to animals (probability) and whether animals’ primary purpose is to serve as entertainment (fidelity). Although the orca Tilikum was involved in trainer deaths, it is clearly SeaWorld who is positioned as culpable in the documentary, having been shown to have unnaturally captured the whale, forcing him to perform, and keeping him in abusive conditions, none of which support SeaWorld's “conservation” narrative. By focusing on the story of one 
orca and claiming that he was mistreated from the moment that he was "kidnapped" from his mother to being housed in a "floating steel box" and forced to perform, the viewer is encouraged to understand that the whale was essentially driven to violence by an abusive corporation, not a caring one. The ability of the film to remediate SeaWorld's own footage, and then PETA's promotion and use of that content, doubly calls into question SeaWorld's legitimacy.

That is, the documentary takes footage that had been used by SeaWorld in the past to demonstrate the positive side of their parks and reframes the same footage to highlight the messages of animal abuse and ethical breaches, pushing viewers to rethink their previous experiences at their parks or images of SeaWorld. It is important to note that PETA had the option of selecting this message (Blackfish) in order to push its message on its "SeaWorld of Hurt" website and elsewhere. Remediation, in this case, empowers the activist group to employ the documentary in order to further its cause. In fact, the documentary creates an ironic reframing of the performances and physical spaces of the parks. Images of the orcas are reframed by PETA to demonstrate the abuse of the animal. In turn, the documentary itself and the activists' use of the film both work to reshape viewers' understanding of animal rights and entertainment, conflicting with SeaWorld's narrative and chipping away at its legitimacy as the controversy wore on. 
In other words, because PETA first framed the issue of animal treatment through the use of the documentary's narrative, it was particularly difficult for SeaWorld to respond. The corporation was, in many ways, trapped in that narrative and was eventually forced to attempt to manage the altered image of entertainment/animals and the institution. Indeed, PETA's ongoing pressure through a campaign about forced orca breeding (one angle in the film), covered by major media outlets, saw its website hits moving from about 30 per day pre-Blackfish release to more than one million by 2015 (Chattoo, 2017). Thus, PETA's initial handling of the movie created a unique rhetorical situation in which the corporation was always placed on the defensive and bound by the fallout from the rhetorical fracture. By the end of 2013, however, SeaWorld went from downplaying its 9\% fall in attendance to, although it never identifies Blackfish by name, appearing to react to something (Green, 2015: para. 9).

Phase Two: SeaWorld's “Truth” Videos and Image Ads Respond to Remediation The growing media attention to PETA/Blackfish then created the need for SeaWorld to create a series of image advertisements to address the situation. SeaWorld initially reacted by attempting to reframe some of the claims made by the documentary as well as the activist organization, explaining that "experts" disagreed with the interpretation that PETA and the documentary producers put forward. In December of 2013 (five months 
after Blackfish came out), SeaWorld, at first ignoring heightened expectations to respond online, chose to take out traditional full-page image advertisements in several national newspapers that responded to accusations made against the park (Kaufman, 2013). These image ads continued to argue for the probability and fidelity of SeaWorld's claim that it was a place where consumers could engage in ethical animal entertainment. The title of the first advertisement, and a phrase that was used again in future messages, was "The Truth is in Our Parks and People." Attempting to respond to the "window on the world" ethos that Blackfish used, the campaign put forth "the truth” as told by "SeaWorld's animal advocates,” explaining, “We are 1,500 scientists, researchers, veterinarians, trainers, marine biologists, aquarists, aviculturists, educators and conservationists who have dedicated our lives to the animals in our care..." The advertisement then refuted the charges made against the organization in the documentary, emphasizing their investment in the care of the animals at their various parks and their focus on research, education, and conservation. Rather than falling for the arguments put forth in the documentary, the company argued, just look at the "truth" that is presented in the parks. This clear attempt to bolster the ethos of the company might have worked more effectively in previous times because of readers' inability to quickly "fact-check" its claims, but it was not enough in the digital age, with celebrities tweeting their support of PETA and the movie, for example, 
helping to keep media coverage building and moving beyond "insular, niche activism" to a broader audience (Chattoo, 2017: para. 9).

With SeaWorld's profits continuing to plummet, the organization recognized the need to expand its response message to the digital realm in a plea to support its legitimacy. It began to support its corporate story in earnest, calling Blackfish “propaganda,” and chastising its creators for “emotionally manipulative” footage (Green, 2015: para. 12). Although the corporation tried to incorporate the documentary’s style into its messages, SeaWorld's initial attempt to counter the narrative put forth by Blackfish did not match the visual story that the film told in terms of the medium and the content of the advertisement. In January of 2014, SeaWorld introduced the “Truth” videos on their YouTube channel, featuring employees discussing Blackfish and accusations made by PETA, and highlighting the positive aspects of the organization, drawing from the "pseudo-expert" ethos popular in digital culture. These videos used a similar visual appeal, but lacked the narrative emotional appeal that the remediated documentary provided to PETA. One observer pointed out that Tilikum's story evoked empathy, with his story resonating with audiences because Tilikum, as the “victim,” elicited compassion (Chattoo, 2017: para. 12). Drawing from the documentary style, the “Truth” videos instead focused on "talking heads” by conducting short interviews with SeaWorld employees who argued against the Blackfish 
portrayal of the parks. With more than 55 videos posted between January and December of 2015, SeaWorld implored the audience to trust the parks and to see "the truth" through the visual evidence, attempting to boost the fidelity and probability of its story.

Similarly, SeaWorld's television outreach lacked the resonance of Tilikum's story, mimicking Blackfish's style but unable to capitalize on the emotional power needed to foster trust in today’s digital realm. A SeaWorld commercial that aired on major television stations around this time featured a woman who, viewers were told, works as a veterinarian at the park and a man who is in charge of animal rescue. The two employees sit in front of the camera, appearing to have a frank discussion with the viewer. Let us "tell you some facts about SeaWorld,” they say. The animals are "healthy,” they are "thriving,” they say. In fact, the veterinarian claims, she “wouldn’t work here if they weren’t.” The two figures were positioned as protectors of the animals, in this case; their presence was proof of the claims they made and served as a visual confirmation of the credibility of the company and its parks. PETA, however, continued to attack the legitimacy of these arguments.

Because Blackfish pulls from the ethos of the documentary genre, SeaWorld attempted to mimic that style with these versions of the "truth" of its parks. The documentary, however, put forth such a strongly negative narrative about the corporation that SeaWorld appeared indefensible. As one reviewer wrote of the film, “Through the 
rueful voices of former trainers and whale experts, a narrative driven by disillusion and regret unfolds as the trainers point to a gap between SeaWorld's public image and behindthe-scenes reality” (Catsoulis, 2013: para. 2). Attempts to overcome this negative narrative needed to be very effective. Although the rhetorical style of SeaWorld's response was similar, the advertisements were primarily reactive and defensive from an issues management perspective. Coupled with PETA's additional remediation-based attacks, Sea World continued to lose control of the narrative and was forced to deal with changing discourse about animal rights brought about by rhetorical fracture.

\section{PETA’s Counter Parody Advertisement}

PETA continued to take advantage of SeaWorld's weak response to its legitimacybased attack in its next round of advertisements. Deploying hypermediation, it produced a detailed parody of the very commercial that sought to cast SeaWorld employees as the “good guys.” In the television ad, a male and female actor portray SeaWorld employees and are placed in similar poses and with similar backdrops as the original SeaWorld advertisement. From the subtitles, viewers learn that the woman is a "Fish doctor and stuff” and the man is an “Orca masturbater” (a play off of claims about SeaWorld’s forced breeding activities). The actors then mimic the SeaWorld commercial, explaining that “There are some facts about SeaWorld that we'd like you to know” and pointing out that 
SeaWorld must think we are "really fucking stupid" to buy their arguments. In the style of a "mockumentary," PETA playfully uses the ethos of the documentary genre to poke fun at SeaWorld for attempting to borrow from the same type of rhetorical style. The replication of the SeaWorld commercial scenes, the fake position titles, and the satire in the actors' statements all work together to remind viewers that the company’s commercials serve one purpose - to frame SeaWorld as responsible despite mounting evidence to the contrary. PETA’s messages not only call SeaWorld employees into question, but also reposition them as the enemy. Hypermediation serves to heighten the company’s illegitimacy, continuing to fracture SeaWorld's “good guy” narrative.

Phase Three: PETA Gets the Last Word Through Hypermediation SeaWorld's message changed radically in March of 2016. After months of attempting to combat PETA’s attacks, the company’s strategies changed after bringing in Joel Manby as their new CEO (Fry, 2016). Deciding to phase out orcas as part of the park shows and to house them in improved environments, SeaWorld began to explain their change in heart through a national television campaign also featured online (Wallace, 2016). Opening on a ray of sunshine breaking through the ocean water, the narrator begins to reflect on the role of orcas at the parks: 
Some say, "Free the whales.” For them, nothing else is acceptable. But nothing could be worse for the whales. Most of the orcas at SeaWorld were born there. Sending them into the wild wouldn't be noble. It could be fatal. When they freed Keiko, the killer whale of movie fame, the effort was a failure and he perished. The commercial first recognizes the activists’ position without admitting any wrongdoing. The words, in fact, put forth the argument that the activists' story cannot be trusted when it comes to the health of the animals, making SeaWorld's narrative about "animal welfare” plausible. At the same time, SeaWorld then indicates a commitment to changing: But we also understand that times have changed. Today, people are concerned about the world’s largest animals like never before. So, we too must change. That's why the orcas in our care will be the last generation at SeaWorld. There will be no more breeding. We're also phasing out orca theatrical shows. They'll continue to receive the highest standard of care available anywhere. And guests can come to see them simply being their majestic selves. Inspiring the next generation of people to love them as you do.

Moving from the ominous narrative of Tilikum and Blackfish to that of the joyful Keiko and Free Willy (a 1993 film about a boy who befriends a captive orca and ultimately frees 
him), SeaWorld attempts to take the moral high ground (Bostdorff, 1992)— to be "noble"-in changing the way it treats orcas.

PETA, however, responded quickly (within four days) with a parody of the SeaWorld advertisement. Again mimicking the company’s style, PETA’s web-based video opens with the exact lines that SeaWorld used while showing footage of orcas swimming through the ocean. After mirroring the opening wording, the narrator sarcastically asks, See? Look how much these wild orcas are suffering. It’s sad really. Whales don't want to be out there or in a seaside sanctuary. Because you know what whales hate? The ocean. They hate it. It's like telemarketers to them. Or paper cuts. Or wet socks. But times have changed, and people have been giving us a lot of shit about this. Like, a lot. So we too must change.

PETA again used the corporation's strategies against it, mocking its words, music choice, images, and claims, encouraging viewers to not only question the validity of the company's arguments, but to laugh at its attempts to explain itself. Remediation calls its messages into question, but the speed with which PETA hypermediated SeaWorld's message afforded it a rapid response platform. By 2017, SeaWorld's narrative continued to feature its commitment to change rather than defend its practices and philosophy. Early on, both organizations attempted to sway the viewers to see the orcas' existence through 
their narratives, but PETA's savvy use of remediation and hypermediation made it impossible for SeaWorld's story to remain plausible and justifiable, threatening its legitimacy. PETA used digital media to call into question the ways that SeaWorld treats animals and the company had to respond to this conversation.

\section{Conclusion and Implications}

The public relations war between PETA and SeaWorld provides insight into the world of digital activism, showing how activist groups help gradually fracture prevailing narratives in order to encourage new perspectives and policies. Although PETA was not solely responsible for turning the tide against SeaWorld, it was and is the most active voice in challenging SeaWorld's interpretation of its practices, with observers noting that "it is hard to deny” PETA's use of the "Blackfish effect” in creating a “steady negative impact that culminated in dramatic corporate policy change” (Chattoo, 2017: para. 13). In addition to ending the orca shows and breeding programs, PETA continues to help shape new perspectives on SeaWorld's commitment to animal welfare. A Lexis-Nexis news coverage search spanning the years 1990-2016 shows the turn away from viewing the company as offering education and delight to visitors to one that is perceived as a purveyor of animal cruelty, shifting from “conservation” and “fun” (St. Louis Post Dispatch, 1990: para. 1), where families "giggled as we reminded ourselves about the sea otter show and dancing 
dolphins” (Posner, 2007: para. 23), to coverage wondering “How do you sleep knowing you imprison innocent animals?” (Griswold, 2015: para. 2). In addition to these rhetorical shifts, SeaWorld investors filed a lawsuit against the company arguing that the organization downplayed the ramifications of activists on its declining ticket sales (Fry, 2016). Although that case was eventually dismissed, in 2017 investors again sought a legal channel to force SeaWorld to admit the role of the controversy in deceiving investors, with the Department of Justice launching a criminal fraud investigation. Similarly, in 2014, the U.S. House of Representatives considered proposed legislation (nicknamed the "Blackfish bill”) that proposed studying the impact of captivity on orcas and other marine mammals, indicating a potential shift in policies (Duhon et al., 2016). Although we do not claim a one-to-one connection between PETA’s rhetorical strategies and SeaWorld's policy change, we do demonstrate how, through remediation and hypermediation, PETA helps rhetorically shift perceptions and ultimately policies by challenging the legitimacy of SeaWorld's narrative. Along with other activist voices, PETA understood the state of the issue, the animal rights movement, and "where and how a story might be positioned to fuel change” (Chattoo, 2017: para. 7). For its narrative to be legitimate and help it emerge from the crisis, SeaWorld's story needed to “tell a credible story, one that has factual fidelity 
that can withstand the scrutiny of reporters, governmental investigators, and concerned citizens” (Heath and Palenchar, 2009: p. 297). It did none of these.

It is important to recognize that although the type of rhetorical fracture identified may differ, the takeaway is the same: it is far easier for activists to cultivate outrage through social media platforms that may culminate in changes in corporate practice. Activists use social media generally to level the playing field, pressure organizations, and damage organizational reputation (Swann, 2017); here, PETA used unrelenting rhetorical fracture to keep SeaWorld on the defensive since 2013. By the end of 2017, the company had lost another \$200 million, another CEO stepped down, and attendance continued to decline (Smith, 2018). We predict that scholars will observe how rhetorical fracture takes different forms other than the hyper/remediation detailed in this case, but we show how some digital activists upend the power balance through their abilities to react quickly, to mock the credibility of the corporation, and to playfully interact with corporate narratives. The hypermediated controversy put SeaWorld at a disadvantage because of the slow response time that is often indicative of a sizeable organization and because of the constraints on the message style that they were able to adopt. For example, SeaWorld could not be as edgy, as humorous, as sarcastic, as dark, or as sexual, as PETA. PETA had the freedom to change its message and to acknowledge its foe. It could steal SeaWorld's 
message, using it for mockery, and do it almost instantly through its social media campaign. As SeaWorld CEO Joel Manby explained it, “SeaWorld had lost the public’s trust. 'I mean, we can say that what Blackfish was saying was not true, and we have facts to back it up, but if we're the only ones saying it, we're not going to have the credibility to win that'” (Wallace, 2016: para. 36). Manby recognized that SeaWorld had to find a way to take control of the company's narrative, and with the use of Blackfish as the opening salvo, the organization was at a disadvantage that PETA's activism only made more apparent. As a result, from the narrative perspective, to successfully emerge from the crisis, SeaWorld needed to frame its story "in terms of what happened, what response is being made, and where that effort leads” (Heath and Palenchar, 2009: p. 296). As many have pointed out, however, SeaWorld changed its story too late; the campaign against the corporation continues. Most recently, PETA took advantage of the death of a polar bear at one of SeaWorld's locations to point out the continued problems with animal treatment at the parks (PETA, “Polar Bear,” 2017) and posted billboards asking Californians to "shun the abusement park” (PETA, “Ad Blitz,” 2017). Thus, PETA continues to respond swiftly and effectively to the corporation's messages, offering its counter narrative that continues to question the company's legitimacy and keeps the issue from fading from public attention. 
Though it is likely that other activists will continue to attack targets by co-opting their media, it is rhetorical fracture at the message level itself, not just the specific medium used, that provides activists with a fundamental advantage. The openings created by the changes in the digital media environment allow claims to circulate with a larger audience, with growing outrage garnering mainstream media attention and increased issue legitimacy, pushing an issue through the issues management lifecycle. Mainstream media may either ignore or re-appropriate forms of digital activism in ways that support the dominant narratives of organizations, but activists’ perspectives are also shared through those channels, working to challenge targets (Jackson and Wells, 2015). Indeed, mainstream media actively featured PETA’s perspective in the SeaWorld case. CNN premiered Blackfish and interviewed SeaWorld officials, supporting PETA's narrative. Ultimately, strategies of rhetorical fracture rely on "virality” to generate interest and media coverage, but do move beyond merely digital forms of activism to influence policy debates and changes in practice (Jackson and Wells, 2015: p. 949). Indeed, PETA’s ability to remediate Blackfish virally shared the film’s clear “clarion call” to action-release the orcas from captivity—with audiences far beyond the film itself (Chattoo, 2017: para. 11). Public relations literature must continue to account for the efforts of such activists in gradually "pushing the needle” to new expectations for corporate practice among 
consumers. Our discipline should better understand how these forms of radical activism encourage broad societal changes. Indeed, through rhetorical fracture, activists capitalize on the relationship between power and legitimacy, helping them exert influence by delegitimizing an opponent's reputation (Heath, 2009; Smith and Ferguson, 2010; Spar and La Mure, 2003). As a result, PETA challenges the status quo about animal welfare by encouraging public debate and corporate disclosure, ultimately contributing to the public's ability to make enlightened choices (Heath, 2009). PETA uses rhetorical fracture to challenge SeaWorld in some uncomfortable, harsh ways, but, like other activist groups, its arguments about animal welfare help to "add value to the dialogue of society by seeking to raise standards, or values, on which public policy is founded” (Heath and Waymer, 2009: p. 209). We thus view the role of activist groups like PETA through more of an agonistic perspective, where conflict is seen as central in producing social change (Laclau and Mouffe, 1998). As such, our focus is less about how PETA creates common ground with SeaWorld, because although such activists seek to remain oppositional, we should better account for how they use rhetorical techniques to drive targets to enacting meaningful (measurable) action (e.g., Gong, 2015; Jackson and Wells, 2015; Scudder and Mills, 2009; Stokes and Rubin, 2010; Weaver, 2001). Understanding how activists create effective persuasive messages through strategies like rhetorical fracture pays needed attention to 
questions of power and the ability to alter perceptions of corporate reputation, answering the call to bring more attention to strategic messaging in the digital realm (Coombs and Holladay, 2012; Smith and Ferguson, 2013).

\section{Notes}

${ }^{1}$ Digital social advocacy is defined as "an organized public effort, making collective claims of a target authority(s) in which civic initiators or supporters use digital media" (Edwards et al., 2013: p. 10).

2 Activism scholarship explores generally how activists seek to create change or "rectify" identified conditions as well as how groups maintain commitment to a movement or cause (Smith and Ferguson, 2010: p. 397).

${ }^{3}$ Many public relations scholars rely on the legitimacy concept in a variety of other contexts (e.g., Boyd, 2000, 2009; Hearit, 1995; Meisenbach and McMillan, 2006; Seeger, 1986; Vaara et al., 2006).

${ }^{4}$ Another corporation used remediation to challenge its attacker, simply posting a copy of an original taped interview online to show how its opponent had strategically edited footage for the story (Stokes, 2005) 


\section{References}

Alinsky S (1971) Rules for Radicals: A Practical Primer for Realistic Radicals. New York: Vintage Books.

Allen E (2012) “SeaWorld’s whales are not slaves”: Judge throws out PETA lawsuit saying the $13^{\text {th }}$ amendment only applies to humans. Daily Mail. Available at: www.dailymail.co.uk/news/article-2098671/Judge-throws-PETA-lawsuit-saying13th-amendment-applies-humans.html (accessed 30 May 2017).

Atkins-Sayre W (2010) Articulating identity: People for the Ethical Treatment of Animals and the animal/human divide. Western Journal of Communication, 74: 309-328.

Awesomeocean (nd) The motives behind PETA's attack on SeaWorld. Awesome Ocean. Available at: http://awesomeocean.com/top-stories/motives-behind-petas-attacksseaworld/ (accessed 10 November 2017).

Berkowitz S (2003) Originality, conversation and reviewing rhetorical criticism. Communication Studies, 54: 359-363.

Bolter J and Grusin R (1999) Remediation: Understanding New Media. Boston: MIT Press.

Bortree DS and Seltzer T (2009) Dialogic strategies and outcomes: An analysis of environmental advocacy groups’ Facebook profiles. 
Public Relations Review, 35: 317-319.

Bostdorff D (1992) ‘The decision is yours’ campaign: Planned Parenthood’s characteristic argument of moral virtue. In Toth EL and Heath RL (eds.) Rhetorical and Critical Approaches to Public Relations. Hillsdale, NJ: Lawrence Erlbaum, pp. 301-314.

Bowen S and Heath RL (2007) Narratives of the SARS epidemic and ethical implications for public health crises. International Journal of Strategic Communication, 1: 7391.

Boyd J (2000) Actional legitimation: No crisis necessary. Journal of Public Relations Research, 12: 341-353.

Boyd J (2009) The legitimacy of a baseball number. In Heath R, Toth E and Waymer D (eds.) Rhetorical and Critical Approaches to Public Relations II. New York, NY: Sage, pp. 154-169.

Brooks KP and Waymer D (2009) Public relations and strategic issues management challenges in Venezuela: A discourse analysis of Crystallex International Corporation in Las Cristinas Public Relations Review, 35: 31-39.

Bryan B (4 August 2016) SeaWorld destroyed after reporting a disastrous attendance drop. Business Insider. Available at: nordic.businessinsider.com/seaworld-earningsattendance-drop-2016-8/ (accessed 30 May 2017). 
Burke K (1959) Attitudes Towards History. Los Altos, CA.

Campbell KK and Burkholder TR (1997) Critiques of Contemporary Rhetoric $\left(2^{\text {nd }}\right.$ edition). Belmont, CA: Wadsworth.

Campbell KK (1998) Inventing women: From Amaterasu to Virginia Woolf. Women’s Studies in Communication, 21: 111-126.

Catsoulis J (18 July 2013) Do six-ton captives dream of freedom? “Blackfish,” a documentary, looks critically at SeaWorld. New York Times. Available at: www.nytimes.com/2013/07/19/movies/Blackfish-a-documentary-looks-criticallyat-seaworld.html (accessed 30 May 2017).

Chattoo C B (2017) Anatomy of “The Blackfish Effect.” Huffington Post. Available at: www.huffingtonpost.com/caty-borum-chattoo/anatomy-of-the -Blackfish_b_9511932.html (accessed 20 September 2017).

Cheng Y (2016) Activism in China: Power and confrontation strategies in a Chinese village. Chinese Media Research, 12(2): 90-103.

Condit CM (1994) Hegemony in a mass mediated society: Concordance about “reproductive technologies.” Critical Studies in Mass Communication, 11: 205230.

Condit CM and Condit DM (1992) Smoking OR health: Incremental erosion as a public 
interest group strategy. In EL Toth and RL Heath (eds.), Rhetorical and Critical Approaches to Public Relations. Hillsdale, NJ: Lawrence Erlbaum, pp. 301-314.

Coombs, WT (1992) The failure of the task force on food assistance: A case study of the role of legitimacy in issue management. Journal of Public Relations Research, 4: 101-122.

Coombs WT (2006) Code Red in the Boardroom: Crisis Management as Organizational DNA. Westport, CN: Praeger.

Coombs WT and Holladay SJ (2007) The negative communication dynamic: Exploring the impact of stakeholder affect on behavioral intentions. Journal of Communication Management, 11(4): 300-312.

Coombs WT and Holladay SJ (2012) Fringe public relations: How activism moves critical PR toward the mainstream. Public Relations Review, 38(5): 880-887.

Crable RE and Vibbert SL (1985) Managing issues and influencing public policy. Public Relations Review, 11: 3-16.

DeLuca KM, Lawson S, and Sun Y (2012) Occupy Wall Street on the public screens of social media: The many framings of the birth of a social movement. Communication, Culture, and Critique, 5(4): 483-509.

Duhon S, Ellison K and Ragas M (2016) A whale of a problem: A strategic communication 
analysis of SeaWorld Entertainment's multi-year Blackfish crisis. Case Studies in Strategic Communication, 5: 3-37.

Earl J and Kimport K (2011) Digitally Enabled Social Change: Activists in the Internet Age. Cambridge, MA: Massachusetts Institute of Technology.

Edwards HR and Hoefer R (2010) Are social work advocacy groups using Web 2.0 effectively? Journal of Policy Practice, 9: 220-239.

Edwards F, Howard PN and Joyce M (2013) Digital activism and non-violent conflict. Available at SSRN: http://dx.doi.org/10.2139/ssrn.2595115 (accessed 1 June 2017).

Fisher W (1985) The narrative paradigm: An elaboration. Communication Monographs, 52: 347-367.

Fisher W (1987) Human Communication as Narration: Toward a Philosophy of Reason, Value, and Action. Columbia, SC: University of South Carolina Press.

Foss SK (1996) Rhetorical Criticism: Exploration and Practice. Prospect Heights, Illinois: Waveland.

Friedersdorf C (12 March 2014) The fantastical vision for the original SeaWorld. The Atlantic. Available at: www.theatlantic.com/business/archive/2014/03/thefantastical-vision-for-the-original-seaworld/284561/ (accessed 30 May 2017). 
Fry E (14 September 2016) Meet the man trying to save SeaWorld from itself. Fortune. Available at: fortune.com/seaworld-orlando-joel-manby/ (accessed 30 May 2017).

Geiling N (9 November 2015) SeaWorld San Diego ending controversial killer whale shows. Think Progress. Available at: thinkprogress.org/seaworld-san-diegoending-controversial-killer-whale-shows-c0a18bffbb2b (accessed 31 May 2017)

Gong R (2015) Indignation, inspiration, and interaction on the Internet: Emotion work online in the anti-human trafficking movement. Journal of Technology in Human Services, 33: 87-103.

Green C (1 April 2015) A brief history of SeaWorld's 'Blackfish' damage control. Voice of San Diego. Available at: https://www.voiceofsandiego.org/topics/news/a-briefhistory-of-seaworlds-blackfish-damage-control/ (Accessed 10 November 2017)

Greenberg J and MacAulay M (2009) NPO 2.0? Exploring the web presence of environmental nonprofit organizations in Canada. Global Media JournalCanadian Edition, 2: 63-88.

Griswold A (2015) Why would companies ever think a campaign like \#AskSeaWorld is a good idea? Slate. Available:

http://www.slate.com/blogs/moneybox/2015/03/27/_askseaworld_t witter_amas_are_a_terrible_idea_and_yet_companies_do_them.html 
Guo C and Saxton GD (2014) Tweeting social change: How social media are changing nonprofit advocacy. Nonprofit and Voluntary Sector Quarterly, 43: 57-79.

Hearit K (1995) “Mistakes were made”: Organizations, apologia, and crises of social legitimacy, Communication Studies, 46: 1-17.

Heath RL (1994) Management of Corporate Communication: From Interpersonal Contacts to External Affairs. Hillsdale, NJ: Lawrence Erlbaum.

Heath RL (1997) Strategic Issues Management: Organizations and Public Policy Challenges. Thousand Oaks, CA: Sage.

Heath RL (2006) Onward through the fog: Thoughts on public relations’ research directions. Journal of Public Relations Research, 18: 93-114.

Heath RL (2009) The rhetorical tradition: Wrangle in the marketplace. In Heath R, Toth E and Waymer D (eds.) Rhetorical and Critical Approaches to Public Relations II. New York, NY: Sage, pp. 17-47.

Heath RL and Palenchar MJ (2009) Strategic Issues Management: Organizations and Public Policy Challenges. Thousand Oaks, CA: Sage.

Heath RL and Waymer D (2009) Rhetorical and critical approaches to public relations II. Activist public relations and the paradox of the positive: A case study of Frederick Douglass' “Fourth of July Address” In Heath R, Toth E and Waymer D (eds) 
Rhetorical and Critical Approaches to Public Relations II. New York, NY: Sage, pp. 195-215.

Henderson A (2005) Activism in 'paradise': Identity management in a public relations campaign against genetic engineering. Journal of Public Relations Research, 17: 117-137.

Hon L (2015) Digital social advocacy in the Justice for Trayvon Campaign. Journal of Public Relations Research, 27(4): 299-321.

Jackson SJ and Welles BF (2015) Hijacking \#myNYPD: Social media dissent and networked counterpublics. Journal of Communication, 65: 932-952.

Kaufman A (20 December 2013) SeaWorld uses newspaper ads to strike back at “Blackfish” charges. Los Angeles Times. Available at: articles.latimes.com/2013/dec/20/entertainment/la-et-mn-seaworld-Blackfish-adsnewspaper-20131220 (accessed 31 May 2017).

Kent ML (2010) What is a public relations “crisis?” Refocusing crisis research. In: Coombs WT and Holladay SJ (eds.) Handbook of Crisis Communication. Oxford, England: Wiley/Blackwell, pp.705-712.

Laclau E and Mouffe C (1998) Post-Marxism without apologies. In S Simm (ed.), PostMarxism, a reader. Edinburgh: Edinburgh University Press, pp. 56-68. 
La Monica PR (24 March 2015) SeaWorld Says PETA “lies” about killer whales. CNN Money. Available at: money.cnn.com/2015/03/24/investing/seaworld-adcampaign-Blackfish-peta/ (accessed 31 May 2017).

Madden S, Janoske M and Briones R (2015) The double-edged crisis: Invisible Children’s social media response to the Kony 2012 campaign. Public Relations Review, 42: 38-48.

Meisenbach RJ and McMillan JJ (2006) Blurring the boundaries: Historical developments and future directions in organization rhetoric. Communication Yearbook, 30: 99-141.

Mundy DE (2013) Updating pride: How 21st century gay pride organizations strategically use social media to manage relationships with key stakeholders. International Public Relations Research Conference 16, Conference Proceedings.

Neate R (2015) SeaWorld sees profits plunge 84\% as customers desert controversial park. Available at: www.theguardian.com/us-news/2015/aug/06/seaworld-profitsplunge-customers?CMP=share_btn_link (accessed 20 September 2017).

Nichols B (1991) Representing Reality: Issues and Concepts in Documentary. Bloomington, IN: Indiana Press. 
Obar JA, Zube P and Lampe C (2012) Advocacy 2.0: An analysis of how advocacy groups in the United States perceive and use social media as tools for facilitating civic engagement and collective action. Journal of Information Policy, 2: 1-15.

Olson L, Finnegan C and Hope D (2008) Visual Rhetoric: A Reader in Communication and American Culture. Thousand Oaks, CA: Sage.

Papacharissi Z and de Fatima Oliveira M (2012) Affective new and networked publics: The rhythms of news storytelling on \#Egypt. Journal of Communication, 62: 266282.

People for the Ethical Treatment of Animals (23 May 2017) Ad blitz counters SeaWorld’s, urges Los Angelinos to shun “abusement” park. Available at: www.seaworldofhurt.com/peta-launches-anti-seaworld-ad-blitz-los-angeles/ (accessed 31 May 2017).

People for the Ethical Treatment of Animals (14 January 2017) It’s over for Ringling Bros. Available at: www.peta.org/blog/ringling-bros-its-over/ (accessed 31 May 2017).

People for the Ethical Treatment of Animals (18 April 2017) Polar bear Szenja dies alone of a broken heart, PETA believes. Available at: http://www.seaworldofhurt.com/seaworld-separate-polar-bear-best-friends/ (accessed 31 May 2017). 
Petray TL (2011) Protest 2.0: Online interaction and aboriginal activists. Media, Culture, and Society, 33: 923-940.

Posner A (28 July 2007) Fun at theme park helps wash away bad memories. Sarasota Herald-Tribune, BCE4.

Schwarz A (2012) Stakeholder attribution in crises: The effects of covariation information and attributional inferences on organizational reputation. International Journal of Strategic Communication, 6: 174-195.

Scudder JN and Mills CB (2009) The credibility of shock advocacy: Animal rights attack messages. Public Relations Review, 35: 162-164.

SeaWorld (nd) What we do. Available at: seaworldentertainment.com/en/what-wedo/welcome (accessed 31 May 2017).

Seeger M (1986) CEO performance: Lee Iacocca and the case of Chrysler. Southern States Communication Journal, 52: 52-68.

Shirky C (2008) Here Comes Everybody: The Power of Organizing Without Organizations. New York: Penguin.

Smith A (27 February 2018) SeaWorld CEO steps down as attendance slides. CNN Money. Available: http://money.cnn.com/2018/02/27/news/companies/seaworldceo-joel-manby-steps-down/index.html 
Smith MF and Ferguson DP (2001). Activism. In Heath RL (ed.), Handbook of Public Relations. Thousand Oaks, CA: Sage, pp. 291-300.

Smith MF and Ferguson, DP (2010) Activism 2.0. In Heath, RL (ed.), The Sage Handbook of Public Relations (2nd edition). Thousand Oaks, CA: Sage, pp. 395407.

Smith MF and Ferguson DP (2013) 'Fracking democracy': Issue management and locus of policy decision-making in the Marcellus Shale gas drilling debate. Public Relations Review, 39: 377-386.

Sommerfeldt E (2011) Activist online resource mobilization: Relationship building features that fulfill resource dependencies. Public Relations Review, 37(4): 429431.

Spar DL and La Mure LT (2003) The power of activism: assessing the impact of NGOs on global business. California Management Review, 45 (3): 78-101.

Stewart CJ, Smith CA and Denton RE (2007) Persuasion and Social Movements. Long Grove, IL: Waveland Press.

St. Louis Post-Dispatch. (1990) Company sees SeaWorld as Conservation. St. Louis Post Dispatch, 10 October, 4. 
Stokes AQ (2005) Metabolife’s meaning: A call for the constitutive study of public relations. Public Relations Review, 31: 556-565.

Stokes AQ (2013) You are what you eat: Slow Food USA's constitutive public relations. Journal of Public Relations Research, 25: 68-90.

Stokes AQ and Rubin D (2010) Activism and the limits of symmetry: The public relations battle between Colorado GASP and Philip Morris. Journal of Public Relations Research, 22(1): 26-48.

Swann P (2017) From bashtags to geobombing: Modern-day digital guerilla tactics. In Austin, L and Jin, Y (eds.), Social Media and Crisis Communication. New York: Routledge, pp. 335-350.

Uysal N and Yang A (2013) The power of activist networks in the mass selfcommunication era: A triangulation study of the impact of WikiLeaks on the stock value of Bank of America. Public Relations Review, 39(5): 459-469.

Vaara E, Tienari J and Laurila J (2006) Pulp and paper fiction: On the discursive legitimation of global industrial restructuring, Organization Studies, 27: 789 - 810.

Veil S, Reno J, Friehaut R and Oldham J (2015) Online activists vs. Kraft foods: A case of social media hijacking. Public Relations Review, 41: 103-108. 
Veil S, Sellnow T and Petrun E (2012) Hoaxes and the paradoxical challenges of restoring legitimacy: Dominos’ response to its YouTube crisis. Management Communication Quarterly, 26: 322-345.

Wallace B (4 May 2016) SeaWorld breached: Score one for the cetaceans. New York Magazine. Available at: http://nymag.com/daily/intelligencer/2016/04/seaworldtilikum-orcas.html (accessed 31 May 2017).

Weaver CK (2001) Dressing for battle in the new global economy: Putting power, identity, and discourse into public relations theory. Management Communication Quarterly, 15: $279-288$.

Yang A and Taylor M (2010) Relationship-building by Chinese ENGOs’ websites: Education, not activation. Public Relations Review, 36(4): 342-351. 